\title{
Particle Size Distribution and Physicochemical Properties of Pellets Made of Straw, Hay, and Their Blends
}

\author{
Aleksander Lisowski ${ }^{1}$ (C) Patryk Matkowski ${ }^{1}$ Magdalena Dąbrowska ${ }^{1} \cdot$ Michał Piątek $^{1}$ · Adam Świętochowski ${ }^{1}$. \\ Jacek Klonowski ${ }^{1}$. Leszek Mieszkalski ${ }^{2}$. Volodymyr Reshetiuk ${ }^{3}$
}

Received: 7 May 2018 / Accepted: 11 September 2018 / Published online: 18 September 2018

(c) The Author(s) 2018

\begin{abstract}
The aims of the study were (a) the determination of the physicochemical characteristics of properties of pellets made of shredded residue from hay, wheat straw, and their blend at a ratio of 50:50, and (b) the determination of a mathematical model of pellet durability, using a response surface method. Tests were conducted according to applicable standards. As a result of thermal changes during the pressure agglomeration process, the material moisture content of pellets had slightly decreased versus raw three biomasses by $0.50 \%$ w.b. (wet basis) to a final value within the range of $5.56-5.87 \%$ w.b. The pellet properties of the blend were not adequately represented by the arithmetic mean of their components. Pellets made of hay, straw, and their blend, had DM (DM—dry matter) specific densities of 1034, 974, and $1102 \mathrm{~kg} \mathrm{~m}^{-3}$, respectively. The densities showed correlation with calorific values $(\mathrm{r}=0.637)$, which were in the range of $16.07-17.00 \mathrm{MJ} \mathrm{kg}^{-1}$. The pellet durability coefficient correlated negatively with particle size and biomass moisture content. On the basis of previous conclusions, a non-linear mathematical model was formulated to account for the pellet durability coefficient relative to pellet moisture, and the relation of particle sizes and specific density to pellet bulk density.
\end{abstract}

Keywords Biomass $\cdot$ Moisture content $\cdot$ Density $\cdot$ Durability $\cdot$ Calorific value

\section{Statement of Novelty}

Manuscript concerns evaluate the physicochemical properties of biomass and pellets produced from hay, straw and their blend, and to model impact of the moisture content and the product of the mean particle size and the density ratio on pellet's durability, which have not been presented in the available literature so far. The estimated model includes previously unknown relations of moisture content and product

Aleksander Lisowski

aleksander_lisowski@sggw.pl

1 Department of Agricultural and Forest Engineering, Faculty of Production Engineering, Warsaw University of Life Sciences, Nowoursynowska Street 166, 02-787 Warsaw, Poland

2 Department of Production Management and Engineering, Faculty of Production Engineering, Warsaw University of Life Sciences, Nowoursynowska Street 166, 02-787 Warsaw, Poland

3 Department of Automation and Robotic Systems, National University of Life and Environmental Sciences of Ukraine in Kyiv, Kiev, Ukraine of the geometric mean particle size and the specific and bulk density ratios on pellet's durability. It was assumed that from blend of hay and straw at a mass ratio of 50:50 a synergy effect could be given, due to pellet durability, not only to the additive effect.

\section{Introduction}

The supply costs of lignocellulosic feedstock are considerably high owing to the low bulk density of the energy crops, especially for herbaceous biomass $[1,2]$. The cost of feedstock production, handling, transportation, and pre-processing accounts for $40-60 \%$ of the total cost of bio-energy production, while the cost of transportation only accounts for $13-28 \%$ of the total costs [3].

Biomass is often converted into compact forms, such as pellets or briquettes [4], owing to its properties that are primarily dependent on its low-bulk density [5, 6]. In this way, solid fuel properties are significantly improved, and the supply logistics ultimately becomes more efficient and costeffective [7]. Increasing the density of a product makes its 
storage and transportation easier, decreases the required storage volume [8], and ultimately reduces storage and trading costs [9]. Compared to raw materials, formed biomass has a higher calorific value — as high as $19.5 \mathrm{MJ} \mathrm{kg}^{-1}$ —and lower moisture content. This low moisture content is explained by the necessity to impose a reduction in its value before or during pressure agglomeration of raw materials [10].

The efficiency of the pressure agglomeration process also depends on particle sizes. The smaller the particles are, the larger the overall contact surface is. Therefore, the bonds between the particles have higher energy per unit mass, regardless of the material's physicochemical properties [11]. The density of the agglomerates is inversely proportional to particle sizes [12-16]. Mani et al. [1] recommended that the mixture intended to be used for pellet production should have small particle sizes that are not bigger than $3.2 \mathrm{~mm}$. Biomass used by Stelte et al. [17], among which was wheat straw had a particle size between 1 and $3 \mathrm{~mm}$ in diameter and a moisture content $10 \%$ w.b. Recommended particles size for good pellet quality is usually below $5 \mathrm{~mm}$ in diameter $[13,18]$. General, a broad variation of particle size is the best with respect to the pellet quality, but too high amount of fine particles (smaller than $0.5 \mathrm{~mm}$ in diameter) in the raw material has a negative impact on friction and pellet quality [13]. The effects of mechanical compression on biomass particle structures have been reported in previous publications [1, 3, 6, 12-14], and the general impact of the pelleting process of a single biomass type on product quality has been studied [12].

Selection of suitable biomass, its shredding, conditioning, use of additives, and applying of an appropriate pressure agglomeration process, allow the achievement of good pellets quality in terms of their mechanical durability, and the resistance shown by the agglomerate to external loads during storage and transport [19]. The chain of materials and the technological links of production and transport influence the final form of the pellets, which are delivered to the power or combined heat and power plants. In supply logistics, the costs per unit mass are very important [20, 21]. However, it is also necessary to provide a product that is acceptable not only for use as fuel, but also for the fire risk posed by the easily breakable, dust-laden pellets. Dust can be deposited on elements of transport conveyor or it can hover in the air [22]. Both forms of dust, especially dust deposited in a layer often placed on the covers of warmed bearings, are hazardous because they may self-ignite at temperature of $220{ }^{\circ} \mathrm{C}$ that is much lower than the corresponding temperature for dust layers originating from coal $\left(300^{\circ} \mathrm{C}\right)$. To make the pellets less breakable during delivery, they should have high mechanical durability and resistance to external loads imposed during compression, bending, and cutting.

For a better understanding of the pelleting process, compression models have been developed which can help optimise the pressure needed to obtain a better pellet quality. Numerous equations that express the relationship between pressure and time during the compaction of different raw materials are available in literature [12, 24-26]. Experimental designs, data analyses using statistical and evolutionary methods, and further optimisation will offer great advantages, and aid in the determination of the best quality attributes and better understanding of the complex system [23].

The effects of mechanical compression on biomass particle structures have been reported in previous publications $[1,3,6,12-14]$, and the general impact of the pelleting process of a single biomass type on product quality has been studied [12].

For the production of fuel pellets, residues biomasses from the forestry and agricultural sectors are used. These include sawdust, bark, forest residues, cereal residues and energy grasses [14]. The literatures report the use of several lignocellulosic biomasses for solid fuel production, such as: sawdust or residues from different trees [10, 18, 27, 28], cereal straw or residues (wheat, barley, oat, rice) [29-32], corn stover [2, 19, 29, 31, 33], biomasses energy plants (willow, miscanthus, Jerusalem artichoke, Spartina pectinata, big bluestem, switchgrass) [3, 7, 19, 23, 29, 31, 33-35], soybean waste (bark, stalk and defective grains) [18], sugarcane (bagasse, other residues) [18, 36].

However, few studies have been conducted in order to compare different types of biomass and their blends for pellet production. Biofuel pellets were prepared from biomass (pine, chestnut and eucalyptus sawdust, cellulose residue, coffee husks and grape waste) and from blends of biomass with two coals (bituminous and semi anthracite) [37]. It was found that the blends of pine sawdust with 10-30\% of chestnut sawdust were the best for pellets production. Blends of cellulose residue and coals $(<20 \%)$ with chestnut and pine sawdust's did not decrease pellet durability. Monedero et al. [38] suggested that to improve the quality of poplar pellets is good to blend the poplar chips with pine sawdust prior to pelletization. The optimum operational conditions for the blends were as follows: compression die (press way-the way between the beginning of the inlet cone and the end of the straight part of the die hole) of $21 \mathrm{~mm}$ and moisture content at the inlet die around 30\% (dry basis) for blends with poplar content up to $45 \%$ and press way of $19 \mathrm{~mm}$ and $15 \%$ moisture content for poplar with and without additive. Harun and Afzal [39] blended agricultural (reed canary grass, timothy hay and switchgrass) and woody biomass (spruce and pine) and they found that after blending the pellet yield stress values converged the closest to that value for forestry biomass. They concluded that blending low cost and abundant available agricultural biomass with woody biomass could not only result in better mechanical properties but also would help to meet the pellet market demand in future. They hypothesized that blending agricultural biomass with 
current woody biomass based pellets might give direction in the development of new feedstock. Similarly, Stasiak et al. [40] carried out an investigation the blends of pine sawdust with wheat straw and rapeseed straw in different proportions. They found that the pellet density decreased with an increased percentage of two straw types in the blends. Pellet strength decreased with the addition of ground straw. A decrease in the heat of combustion with an increase in the percentage contribution of straw in the blends was observed. In the experiments carried out by Wang et al. [41] of wheat straw blended with rice straw it was found that blending these biomasses can improve the pelletizing properties of wheat straw. These studies have proven that blending with forestry biomass materials can achieve lower energy consumption and better pellet quality during the pelletizing process of crop straw. However, to-this-date, there has been no explanation for the effects of blending of straw with hay.

In Poland, there is a large biomass potential from agriculture, forest, energy plantations, and municipal waste, which are used to pellets production of 900,000 tons in 2015 year [42]. Igliński et al. [43] estimated that Poland produces approximately 23 million tonnes of biomass waste per year. The technically recoverable potential of straw amount 6.7 million tonnes can be increasing to 8.63 million tonnes by 2020. Hay is added to the straw of inferior quality and coming from fallow lands, which in Poland is about 400,000 ha. In this context, the study of straw and hay blends as renewable source with huge potential to pellet production as solid fuels becomes indispensable.

Therefore, the aim of the study was to evaluate the physicochemical properties of biomass and pellets produced from hay, straw, and their blend at a ratio of 50:50 (\% wet basis), under large-scale production conditions, as well as to develop a mathematical model of pellet durability using the response surface modelling approach. The estimated model includes previously unknown relations of moisture content and product of the geometric mean particle size and the specific and bulk density ratios on pellet's durability. The experimental data were processed by variance, correlation and regression analyses and a regression model was finally created. It was assumed that from blend of hay and straw at a mass ratio of 50:50 a synergy effect could be given, due to pellet durability, not only to the additive effect.

\section{Materials and Methods}

\section{Biomass Feedstock}

The wheat straw, hay and their blend at a ratio of 50:50 were used, which were obtained from the private suppliers. Before pelleting, the raw materials were cut and shredded.
The blend of wheat straw and hay was prepared by weighed material portions, $100 \mathrm{~kg}$ each, and placing them in two layers, one on the top of the other on a conveyor belt. The material prepared in this way was transported to the machine (power $132 \mathrm{~kW}$, rotational speed $1200 \mathrm{rpm}$, number of knives 196), where it was initially cut and then it was transported to the beater mill (power $250 \mathrm{~kW}$, rotational speed $1488 \mathrm{rpm}$, number of beaters 160), equipped with a perforated screen with an opening of $8 \mathrm{~mm}$. The material samples were taken from the output of the shredder.

The moisture content of the plant material was measured using the drying-weighting method according to the ASAE S358.2 standard [44]. The samples of $20 \mathrm{~g}$ of each biomass were weighed on electronic scales (WPS 600/C, Radwag) with an accuracy of $0.01 \mathrm{~g}$ and dried at $103 \pm 2{ }^{\circ} \mathrm{C}$ for $24 \mathrm{~h}$.

The shredded materials from hay, straw, and their blend had moisture contents (according to the ASAE S358.2 standard) [44] of $5.80 \pm 0.53 \%, 6.33 \pm 0.12 \%$ and $6.60 \pm 0.20 \%$ w.b. (wet basis), respectively. These biomass samples were transported in the perforated containers to avoid natural agglomeration of particles.

At these moisture contents, the whole mixture of hay, straw, and their blend were separated on a LAB-11-200/UP sieve separator (Eko-Lab, Brzesko, Poland) with vibration stack according to the ANSI/ASAE S319.4 standard [45]. The set of six sieves from the bottom to the top had opening screen dimensions of $0.045,0.056,0.1,0.15,0.212,0.3$, $0.425,0.6,0.85,1.18,1.6$ and $2.36 \mathrm{~mm}$, respectively, and a pan at the bottom. A single sample of hay, straw, and their blend used for separation was $50 \mathrm{~g}$ for each replication. The sieving time was $300 \mathrm{~s}$ and was measured by a stopwatch. The particle fractions were weighed ( $0.01 \mathrm{~g}$ resolution) on WSP 600/C electronic scales (Radwag, Radom, Poland). The test was carried out in 15 replications for each biomass type.

The geometric mean of particle length $\left(x_{g}\right)$, the dimensionless standard deviation $\left(s_{g}\right)$ and the characteristic parameters of particle size distribution were determined according to the formulas widely described in previous literature [46]. The cumulative mass rate of hay, straw, and their blend was approximated by the Rosin-Rammler (RR) model [47].

\section{Pellets Properties}

The pellets were made by a private company Lootor Ltd. located in Słońsk, Poland. Pellets made in pelletiser (power $280 \mathrm{~kW}$, horizontal die, output $3.5 \mathrm{t} \mathrm{h}^{-1}$ ) with nominal die diameter of $8 \mathrm{~mm}$ were produced on the large-scale technological line under comparable conditions. Aligned machine working parameters at nominal rotational speed without overloading allow assuming that the same pressure was applied to pellets in all cases. Test samples of pellets were chosen randomly in the same time as samples of shredded biomass. These biomass samples were transported in the 
tied plastic bags to keep unchanged material moisture content. In the laboratory, the moisture contents of shredded biomass and pellet materials were tested according to the ASAE S358.2 standard [44]. These moisture content values are discussed in the "Results and Discussion" paragraph.

The relation of pellet density to dry matter of specific bulk density $\rho_{j p}$ was calculated on the basis of direct measurements of the heights (at the middle of the sample) and diameters (at two perpendicular directions) in samples using an electronic calliper with an accuracy of $0.01 \mathrm{~mm}$. Each sample was subsequently weighed on an electronic scales (WPS 600/C, Radwag) with an accuracy of $0.01 \mathrm{~g}$. To measure pellets density, the frontal surfaces of pellets were ground by grinding machine, while the perpendicular surfaces were maintained with respect to the axis of the cylinders. During this operation a pellet was placed on angular device and the frontal surfaces of pellet were ground by the grinding wheel.

The bulk density of dry matter $\rho_{b p}$ of the pellets was determined from trials by weighing the sample on the electronic scale using a container that had a volume of $0.002 \mathrm{~m}^{3}$ with an accuracy of $0.01 \mathrm{~g}$.

The gross calorific value $Q_{s}$ of pellet material was determined using a calorimeter (KL-10, Precyzja-BIT), and the net calorific value $Q_{p}$ was then calculated in accordance to Eq. 1 [8]:

$Q_{p}=Q_{s} \frac{100-W}{100}-E_{w}\left(W+H m_{H_{2} O}\right)$,

where $Q_{p}$ is the net calorific value, $\mathrm{kJ} \mathrm{kg}^{-1} ; Q_{\mathrm{s}}$ is the gross calorific value of wet biomass, $\mathrm{kJ} \mathrm{kg}^{-1} ; E_{w}$ is the energy needed to evaporate water under standard conditions per $1 \%$ of water from wet biomass, $\mathrm{kJ} \mathrm{kg}^{-1} ; W$ is the biomass moisture content, \%; $H$ is the hydrogen content in tested sample, $\% ; m_{\mathrm{H}_{2} \mathrm{O}}$ is the mass of water formed in the combustion process per hydrogen unit ( $8.94 \mathrm{~kg} \mathrm{~kg}^{-1}$ of hydrogen).

The hydrogen content in biomass was determined according to the PN-EN 15407:2011 standard [48]. Tests of pellets durability were carried out according to the PN-EN ISO 17831-1:2016-02 standard [49]. The durability coefficient $D U$ was calculated using the formula (Eq. 2),

$D U=100 \frac{m_{A}}{m_{E}}$

where $m_{A}$ is the mass (g) of the sample after the test; $m_{E}$ is the mass $(\mathrm{g})$ of the sample before the test.

\section{Statistical Analysis}

The data were analysed with Statistica (Version 13.3). Hartley's, Cochran's, Bartlett's, and Levene's tests were used to test the homogeneity of variances of the physicochemical parameter values. Deviation from normality was analysed using the Shapiro-Wilk, Kolmogorov-Smirnov, and Lilliefors tests. These tests were performed to check the assumptions of the ANOVA test [50].

The correlations between the physicochemical parameters were calculated using the Pearson correlation test. Statistical significance was determined for $\mathrm{p}$-values that were equal to or $<0.05$.

To develop the model that correlates the durability coefficient to the particle size of the material, pellet moisture, and specific and bulk densities, a non-linear regression method was used.

\section{Results and Discussion}

\section{Particle Size Distribution}

On the basis of the Kolmogorov-Smirnov (K-S) test, it might be assumed that the biomass and the physicochemical parameters of pellets are normally distributed because $p$-values were higher than 0.20 for all distributions parameters (Table 1). The Lilliefors test, corrected by the K-S test $(\mathrm{p}=0.01-0.05)$, and the Shapiro-Wilk test $(p=0.0011-0.0360)$, did not yield positive results. On the basis of the $\mathrm{K}-\mathrm{S}$ test, it was assumed that the physicochemical parameter values were normally distributed.

Based on Hartley's, Cochran's, Bartlett's, and Levene's tests, pellet parameters displayed variance homogeneity, because $p$-values for these parameters were within the range from 0.01 to 0.77 (Table 2). P-values for these tests were lower than 0.01 for milled biomass. However, with some caution, homogeneity of variance can be assumed given that the most important pellet parameters meet these assumptions.

The small values of skewness and kurtosis confirm the compliance of the investigated parameter distributions with the normal distribution. Correspondingly, the skewness and kurtosis parameters were in the ranges of $(-1.46,2.09)$ and $(-1.27,2.99)$, respectively (Table 3$)$.

The particle size density distributions of the hay, straw and their blend were asymmetrical (Fig. 1) with right-hand graphic skewness $G S_{i}$ of small values of $0.15-0.36$ (Table 4). Positive values of graphic kurtosis, $K_{g}=0.96-1.03$ (Table 4), prove the steepness of the distributions. Similar particle distribution trends were observed for switchgrass and barley straw [1], giant miscanthus, Spartina pectinata, Jerusalem artichoke [23], switchgrass, wheat straw and corn stover [29] and straw and hay [46].

Since the cutting and milling the biomass were carried out under the same conditions, with the same settings of the machine parameters, from the characteristics of the particle size distribution it can be concluded that the brittle straw was finer divided than the hay. In the size range up to $0.50 \mathrm{~mm}$, 
Table 1 Values of normal distribution of milled biomass and pellet parameters based on the Kolmogorov-Smirnov (KS, D) and the corrected Lilliefors (p-Lilliefors) and Shapiro-Wilk (WS, W) tests
Table 2 Values of variance homogeneity analysis based on Hartley's, Cochran's, Bartlett's, and Levene's tests, for milled biomass and pellet parameters

\begin{tabular}{|c|c|c|c|c|c|c|}
\hline Biomass & Parameter & $\begin{array}{l}\text { Maximum } \\
\text { D-value }\end{array}$ & $\begin{array}{l}\text { Kolmogorov- } \\
\text { Smirnov K-S } \\
\text { p-value }\end{array}$ & Lilliefors p-value & $\begin{array}{l}\text { Shapiro-Wilk } \\
\text { WS-value }\end{array}$ & P-value \\
\hline \multirow[t]{8}{*}{ Hay } & $x_{g}{ }^{*}$ & 0.20 & $>0.20$ & $<0.15$ & 0.79 & 0.0027 \\
\hline & $s_{g}$ & 0.18 & $>0.20$ & $<0.20$ & 0.85 & 0.0190 \\
\hline & $M C_{b}$ & 0.22 & $>0.20$ & $<0.10$ & 0.83 & 0.0089 \\
\hline & $M C_{p}$ & 0.19 & $>0.20$ & $<0.15$ & 0.82 & 0.0071 \\
\hline & $D U$ & 0.25 & $>0.20$ & $<0.05$ & 0.86 & 0.0253 \\
\hline & $\rho_{j p}$ & 0.12 & $>0.20$ & $>0.20$ & 0.95 & 0.5301 \\
\hline & $\rho_{b p}$ & 0.15 & $>0.20$ & $>0.20$ & 0.87 & 0.0310 \\
\hline & $Q_{p}$ & 0.19 & $>0.20$ & $<0.15$ & 0.84 & 0.0140 \\
\hline \multirow[t]{8}{*}{ Straw } & $x_{g}$ & 0.22 & $>0.20$ & $<0.10$ & 0.84 & 0.0111 \\
\hline & $s_{g}$ & 0.21 & $>0.20$ & $<0.10$ & 0.80 & 0.0038 \\
\hline & $M C_{b}$ & 0.26 & $>0.20$ & $<0.01$ & 0.85 & 0.0162 \\
\hline & $M C_{p}$ & 0.28 & $<0.20$ & $<0.01$ & 0.76 & 0.0011 \\
\hline & $D U$ & 0.19 & $>0.20$ & $<0.15$ & 0.85 & 0.0205 \\
\hline & $\rho_{j p}$ & 0.16 & $>0.20$ & $>0.20$ & 0.95 & 0.4892 \\
\hline & $\rho_{b p}$ & 0.23 & $>0.20$ & $<0.05$ & 0.84 & 0.0134 \\
\hline & $Q_{p}$ & 0.24 & $>0.20$ & $<0.05$ & 0.79 & 0.0027 \\
\hline \multirow[t]{8}{*}{ Blend } & $x_{g}$ & 0.22 & $>0.20$ & $<0.05$ & 0.88 & 0.0547 \\
\hline & $s_{g}$ & 0.25 & $>0.20$ & $<0.05$ & 0.80 & 0.0039 \\
\hline & $M C_{b}$ & 0.19 & $>0.20$ & $<0.15$ & 0.89 & 0.0737 \\
\hline & $M C_{p}$ & 0.18 & $>0.20$ & $<0.20$ & 0.83 & 0.0106 \\
\hline & $D U$ & 0.22 & $>0.20$ & $<0.10$ & 0.80 & 0.0043 \\
\hline & $\rho_{j p}$ & 0.12 & $>0.20$ & $>0.20$ & 0.96 & 0.7277 \\
\hline & $\rho_{b p}$ & 0.14 & $>0.20$ & $>0.20$ & 0.88 & 0.0507 \\
\hline & $Q_{p}$ & 0.25 & $>0.20$ & $<0.05$ & 0.87 & 0.0360 \\
\hline
\end{tabular}

$* x_{g}$ Geometric mean of biomass particle size, $s_{g}$ dimensionless standard deviation, $M C_{b}$ biomass moisture content, $M C_{p}$ pellet moisture content, $D U$ durability coefficient, $\rho_{j p}$ specific pellet density, $\rho_{b p}$ bulk density, $Q_{p}$ calorific value

\begin{tabular}{llllrrrr}
\hline Parameter & $\begin{array}{l}\text { Degrees- } \\
\text { of-free- } \\
\text { dom }\end{array}$ & $\begin{array}{l}\text { Hartley } \\
\text { maximum } \\
\text { F-value }\end{array}$ & $\begin{array}{l}\text { Cochran } \\
\text { C-value }\end{array}$ & Bartlett $\chi^{2}$-value & $\begin{array}{l}\text { P-value } \\
\text { F-value for } \\
\text { Levene's } \\
\text { test }\end{array}$ & $\begin{array}{l}\text { P-value for } \\
\text { Levene's test }\end{array}$ \\
\hline$x_{g}{ }^{*}$ & 2 & 116.92 & 0.53 & 47.57 & $<0.0001$ & 6.80 & 0.0028 \\
$s_{g}$ & 2 & 17.13 & 0.64 & 21.28 & $<0.0001$ & 6.04 & 0.0049 \\
$M C_{b}$ & 2 & 45.69 & 0.90 & 44.48 & $<0.0001$ & 14.93 & $<0.0001$ \\
$M C_{p}$ & 2 & 3.10 & 0.52 & 4.16 & 0.1252 & 2.14 & 0.1297 \\
$D U$ & 2 & 5.32 & 0.46 & 9.77 & 0.0076 & 3.14 & 0.0536 \\
$\rho_{j p}$ & 2 & 5.94 & 0.52 & 9.93 & 0.0070 & 2.82 & 0.0708 \\
$\rho_{b p}$ & 2 & 6.62 & 0.60 & 10.69 & 0.0048 & 5.00 & 0.0112 \\
$Q_{p}$ & 2 & 1.59 & 0.40 & 0.77 & 0.6791 & 0.26 & 0.7693 \\
\hline
\end{tabular}

* $x_{g}$ geometric mean of biomass particle size, $s_{g}$ dimensionless standard deviation, $M C_{b}$ biomass moisture content, $M C_{p}$ pellet moisture content, $D U$ durability coefficient, $\rho_{j p}$ specific pellet density, $\rho_{b p}$ bulk density, $Q_{p}$ calorific value the share of fine straw particles was greater than hay, which is clearly visible in the cumulative graph of the particle size distribution. Share of fine particles decided of lower geometric mean value of straw particle sizes than for hay, which were $0.63 \mathrm{~mm}$ and $0.65 \mathrm{~mm}$, respectively (Table 3). But a larger proportion of longer straw than hay particles affected the increase in dimensionless standard deviations, which were 2.95 and 2.09 , respectively (Table 3 ). The blend of hay and straw resulted in a reduction in the proportion of fine particles and in increase in the share of medium and longer 
Table 3 Mean, minimum, and maximum values, standard deviations (SD), coefficient of variation $(\mathrm{CV})$, skewness and kurtosis of different types of biomasses and pellet distribution parameters

\begin{tabular}{|c|c|c|c|c|c|c|c|c|}
\hline Parameter & Biomass & Mean & Minimum & Maximum & SD & $\mathrm{CV}$ & Skewness & Kurtosis \\
\hline \multirow{3}{*}{$x_{g} *(\mathrm{~mm})$} & Hay & $0.65^{\mathrm{b}}$ & 0.65 & 0.66 & 0.00 & 0.40 & 1.97 & 2.99 \\
\hline & Straw & $0.63^{\mathrm{a}}$ & 0.60 & 0.69 & 0.03 & 4.40 & 1.42 & 1.63 \\
\hline & Blend & $0.69^{c}$ & 0.67 & 0.74 & 0.02 & 3.14 & 1.18 & 1.16 \\
\hline \multirow{3}{*}{$s_{g}$} & Hay & $2.10^{\mathrm{a}}$ & 2.06 & 2.11 & 0.01 & 0.64 & -1.46 & 2.78 \\
\hline & Straw & $2.95^{\mathrm{c}}$ & 2.90 & 3.11 & 0.06 & 1.91 & 1.61 & 2.68 \\
\hline & Blend & $2.37^{\mathrm{b}}$ & 2.33 & 2.44 & 0.04 & 1.55 & 1.34 & 0.82 \\
\hline \multirow[t]{3}{*}{$M C_{b}(\%)$} & Hay & $6.26^{\mathrm{b}}$ & 6.20 & 6.40 & 0.07 & 1.04 & 1.30 & 0.98 \\
\hline & Straw & $5.68^{\mathrm{a}}$ & 5.20 & 6.59 & 0.44 & 7.74 & 1.15 & 0.21 \\
\hline & Blend & $6.56^{\mathrm{c}}$ & 6.40 & 6.80 & 0.13 & 1.97 & 0.80 & -0.33 \\
\hline \multirow[t]{3}{*}{$M C_{p}(\%)$} & Hay & $5.56^{\mathrm{a}}$ & 5.40 & 6.00 & 0.15 & 2.66 & 1.98 & 2.20 \\
\hline & Straw & $5.56^{\mathrm{a}}$ & 5.40 & 6.01 & 0.20 & 3.68 & 1.42 & 0.82 \\
\hline & Blend & $5.87^{\mathrm{b}}$ & 5.60 & 6.60 & 0.26 & 4.45 & 1.59 & 2.50 \\
\hline \multirow[t]{3}{*}{$D U(\%)$} & Hay & $93.15^{\mathrm{b}}$ & 92.72 & 93.98 & 0.39 & 0.42 & 1.13 & 0.37 \\
\hline & Straw & $93.59^{c}$ & 93.18 & 94.50 & 0.39 & 0.42 & 1.28 & 0.84 \\
\hline & Blend & $92.68^{a}$ & 92.52 & 93.04 & 0.17 & 0.18 & 1.37 & 0.90 \\
\hline \multirow[t]{3}{*}{$\rho_{j p}\left(\mathrm{~kg} \mathrm{DM} \mathrm{m}^{-3}\right)$} & Hay & $1034^{\mathrm{b}}$ & 955 & 1100 & 43 & 4.18 & -0.48 & -0.31 \\
\hline & Straw & $974^{\mathrm{a}}$ & 922 & 1065 & 38 & 3.88 & 0.83 & 1.14 \\
\hline & Blend & $1102^{c}$ & 1074 & 1128 & 18 & 1.61 & 0.04 & -1.27 \\
\hline \multirow[t]{3}{*}{$\rho_{b p}\left(\mathrm{~kg} \mathrm{DM} \mathrm{m}^{-3}\right)$} & Hay & $478^{a}$ & 476 & 483 & 2 & 0.37 & 1.97 & 2.34 \\
\hline & Straw & $498^{b}$ & 494 & 507 & 3 & 0.67 & 1.64 & 2.19 \\
\hline & Blend & $514^{\mathrm{c}}$ & 508 & 524 & 5 & 0.89 & 0.57 & -0.19 \\
\hline \multirow[t]{3}{*}{$Q_{p}\left(\mathrm{MJ} \mathrm{kg}^{-1}\right)$} & Hay & $16.07^{\mathrm{a}}$ & 15.96 & 16.32 & 87 & 0.54 & 1.73 & 2.49 \\
\hline & Straw & $17.00^{c}$ & 16.92 & 17.25 & 82 & 0.48 & 2.09 & 2.39 \\
\hline & Blend & $16.64^{b}$ & 16.53 & 16.82 & 69 & 0.41 & 0.85 & 2.67 \\
\hline
\end{tabular}

* $x_{g}$ geometric mean of biomass particle size, $s_{g}$ dimensionless standard deviation, $M C_{b}$ biomass moisture content, $M C_{p}$ pellet moisture content, $D U$ durability coefficient, $\rho_{j p}$ specific pellet density, $\rho_{b p}$ bulk density, $Q_{p}$ calorific value

$\mathrm{a}, \mathrm{b}, \mathrm{c}$-letters next to values represent a significant difference at $\mathrm{P}<0.05$ using Duncan's test

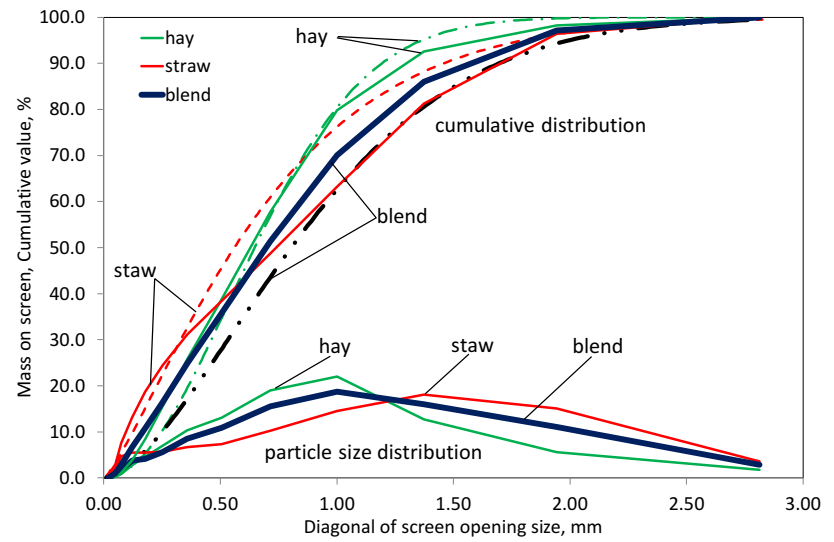

Fig. 1 Shredded biomass particle size distribution and cumulative mass frequency with Rosin-Rammler model (solid lines for real values, discontinuous lines for Rosin-Rammler model)

particles, resulting in an increase in the geometric mean size of the particles to $0.69 \mathrm{~mm}$, i.e. larger than for straw, but with less different particle size, as the dimensionless standard deviation was 2.37 (Table 3). Parameters of particle size distribution in relation to the quality of pellets are described in the further part of the article.

A cumulative mass frequency curves for the RR model against the measuring points are shown in Fig. 1, and the characteristic parameters of the particle size distributions for hay, straw and their blend are presented in Table 4. Size parameters $x_{R}$ of $0.78,0.75$ and $1.01 \mathrm{~mm}$, respectively, were greater than the median size $x_{50}$ of $0.65,0.56$ and $0.80 \mathrm{~mm}$, respectively. The geometric means of hay, straw and their blend particles were shifted to the right with an increase in $x_{R}$, resulting in a mix of decreased fines and increased coarse particles. The RR distribution parameter $n$ (slope), which for hay, straw and their blend were amounted to 1.96, 1.26 and 1.61, respectively, represents the uniformity of particles, that has a strong positive correlation (0.993, Table 5) with effective size $x_{10}(0.25,0.12$ and $0.25 \mathrm{~mm}$, respectively) and a very strong negative correlation $(-0.986)$ with mass relative span $R S_{m}(1.45,2.39$ and 1.81, respectively), which accumulated for $80 \%$ particle mass. The mass relative span was greater than 1.0 , which indicates a wide distribution of 
Table 4 Average values of characteristics parameters of hay, straw and their blends size distribution

\begin{tabular}{|c|c|c|c|c|}
\hline Biomass & Unit & Hay & Straw & Blend \\
\hline$x_{g}$ & $\mathrm{~mm}$ & 0.65 & 0.63 & 0.69 \\
\hline$s_{g}$ & & 2.09 & 2.95 & 2.37 \\
\hline$x_{R}$ & $\mathrm{~mm}$ & 0.78 & 0.75 & 1.01 \\
\hline $\mathrm{p}-x_{R}$ & & $<0.001$ & $<0.001$ & $<0.001$ \\
\hline$n$ & & 1.96 & 1.26 & 1.61 \\
\hline $\mathrm{p}-n$ & & $<0.001$ & $<0.001$ & $<0.001$ \\
\hline $\mathrm{R}^{2}$ & $\%$ & 98.12 & 97.31 & 96.48 \\
\hline $\mathrm{F}$ & & 3293 & 2281 & 1724 \\
\hline $\mathrm{p}-\mathrm{F}$ & & $<0.001$ & $<0.001$ & $<0.001$ \\
\hline$x_{5}$ & $\mathrm{~mm}$ & 0.17 & 0.07 & 0.16 \\
\hline$x_{10}$ & $\mathrm{~mm}$ & 0.25 & 0.12 & 0.25 \\
\hline$x_{16}$ & $\mathrm{~mm}$ & 0.32 & 0.19 & 0.34 \\
\hline$x_{25}$ & $\mathrm{~mm}$ & 0.41 & 0.28 & 0.47 \\
\hline$x_{30}$ & $\mathrm{~mm}$ & 0.46 & 0.33 & 0.53 \\
\hline$x_{50}$ & $\mathrm{~mm}$ & 0.65 & 0.56 & 0.80 \\
\hline$x_{60}$ & $\mathrm{~mm}$ & 0.75 & 0.70 & 0.96 \\
\hline$x_{75}$ & $\mathrm{~mm}$ & 0.92 & 0.97 & 1.24 \\
\hline$x_{84}$ & $\mathrm{~mm}$ & 1.06 & 1.22 & 1.47 \\
\hline$x_{90}$ & $\mathrm{~mm}$ & 1.19 & 1.46 & 1.7 \\
\hline$x_{95}$ & $\mathrm{~mm}$ & 1.36 & 1.80 & 2.00 \\
\hline$I_{u}$ & $\%$ & 14.29 & 4.79 & 9.41 \\
\hline$N_{s g}$ & $\%$ & 65 & 56 & 80 \\
\hline$S_{v}$ & & 56.9 & 92.0 & 70.6 \\
\hline$R S_{m}$ & & 1.45 & 2.39 & 1.81 \\
\hline$C_{u}$ & & 3.00 & 5.83 & 3.84 \\
\hline$C_{g}$ & & 1.13 & 1.30 & 1.17 \\
\hline$x_{g m}$ & $\mathrm{~mm}$ & 0.68 & 0.66 & 0.87 \\
\hline$\sigma_{i g}$ & $\mathrm{~mm}$ & 0.37 & 0.52 & 0.56 \\
\hline$G S_{i}$ & & 0.15 & 0.36 & 0.25 \\
\hline$K_{g}$ & & 0.96 & 1.03 & 0.98 \\
\hline$S T D_{h}$ & & 1.63 & 2.18 & 1.84 \\
\hline$S T D_{l}$ & & 2.03 & 2.95 & 2.35 \\
\hline$S T D_{t}$ & & 1.82 & 2.53 & 2.08 \\
\hline
\end{tabular}

$x_{g}$, geometric mean of biomass particle size, $s_{g}$, dimensionless standard deviation, $x_{R}$, Rosin-Rammler size parameter, $\mathrm{p}-x_{R}, \mathrm{p}-n$, and $\mathrm{p}-\mathrm{F}$, $\mathrm{p}$-value for $x_{R}, n$, and $\mathrm{F}$, respectively, $n$, Rosin-Rammler distribution parameter, $\mathrm{R}^{2}$, coefficient of determination, $I_{u}$, uniformity index $(\%)$, $N_{s g}$, size guide number, $S_{v}$, size range variation, $R S_{m}$, mass relative span, $C_{u}$, coefficient of uniformity, dimensionless, $C_{g}$, coefficient of gradation, dimensionless, $x_{g m}$, graphic mean $(\mathrm{mm}), \sigma_{i g}$, inclusive graphic standard deviation $(\mathrm{mm}), G S_{i}$, inclusive graphic skewness, dimensionless, $K_{g}$, graphic kurtosis, dimensionless, $S T D_{h}, S T D_{l}$, and $S T D_{t}$, distribution geometric standard deviation of the high, low, and total regions, respectively, and $x_{95}, x_{90}, x_{84}, x_{75}, x_{60}, x_{50}, x_{30}, x_{25}, x_{16}$, $x_{10}$, and $x_{5}$ are corresponding particle lengths at 95, 90, 84, 75, 60, $50,30,25,16,10$, and $5 \%$ cumulative undersizes, respectively, these parameters are approximation of particle size distribution particles for each biomass type. This agrees with published trends [29].

The uniformity index value $I_{u}=14.29 \%$ was the smallest for hay particle size distribution, followed by blend and straw with values of $9.41 \%$ and $4.79 \%$, respectively. This parameter is related to the kurtosis and skewness values. If the particle size distribution is flat (the smallest kurtosis $K_{g}$ value of 0.96 was for hay) and symmetric (the lowest coefficient of skewness $G S_{i}$ value of 0.15 was for hay), the mixture is more homogeneous [46]. Therefore, the addition of hay to the straw increased the uniformity of the blend and at the same time longer straw particles can increase the toughness of pellets for fracture. The effect of heterogeneity in particle size on the critical value of number of particle size fractions was investigated by Wiącek and Stasiak [51] for packings with different ratios between diameters of the largest and smallest grains. In mixtures with larger particle size ratios, small particles fit easily within the pores between large particles, thereby increasing the packing density. Kong et al. [27] suggested the longer and wider fibres had the potential as a "solid bridge" to wrap small particles. A mixture of different particle sizes would give optimum pellet quality, because the mixture of particles will make interparticle bonding with nearly no inter-particle spaces. For hay and blend inclusive graphic skewness $G S_{i}$ was of 0.15 and 0.25 , respectively and these biomass particle size distributions were 'fine skewed' $\left(+0.1 \leq G S_{i} \leq+0.3\right)$. For straw the $G S_{i}=0.36$, and the particle size distribution was 'symmetrical' $\left(+0.3 \leq G S_{i} \leq+1.0\right)$. For all biomass types regarding to graphic kurtosis $K_{g}(0.96-1.03)$ the distributions could be termed as a 'mesokurtic' distribution $\left(0.90 \leq K_{g} \leq 1.11\right)$ [52], which is a distribution with the same degree of peakedness about the mean as that of a normal distribution.

The hay and blend values of uniformity coefficient $C_{u}$ 3.00 and 3.84, which were $<4.0$, confirmed the uniformity of these biomass types' particle sizes. For straw a value of uniformity coefficient was amounted to 5.83 and indicated on the diversity of the particle size distribution. The coefficient of gradation $C_{g}$ for particle size distributions, were amounted to $1.13-1.30$ and ranging from 1 to 3 represents a well-graded all biomass types particle size distributions [46].

The inclusive graphic standard deviations $\sigma_{i g}$ descriptively classify the particulate biomass based on the Folk and Ward [53] logarithmic original graphical measures classification [52]. Based on the determined values (Table 4), the hay particle size distribution with inclusive graphic standard deviations of 0.37 was classified as 'well sorted' $\left(0.35<\sigma_{i g}<0.50 \mathrm{~mm}\right)$ and straw and blend with $\sigma_{i g}$ of 0.52 and 0.56 , respectively as 'moderately well sorted' $\left(0.50<\sigma_{i g}<0.70 \mathrm{~mm}\right)$. These classifications would change when the same biomass is converted under different processing machine settings or working parameters, such as 
Table 5 Matrix of Pearson correlation coefficients for hay, straw and their blends particle size distribution parameters $(\mathrm{N}=15)$

\begin{tabular}{|c|c|c|c|c|c|c|c|c|c|c|c|c|c|c|}
\hline Variable & $x_{g}$ & $s_{g}$ & $x_{R}$ & $n$ & $x_{10}$ & $x_{50}$ & $I_{u}$ & $N_{s g}$ & $R S_{m}$ & $C_{u}$ & $C_{g}$ & $S T D_{h}$ & $S T D_{l}$ & $S T D_{t}$ \\
\hline$x_{g}$ & 1.000 & & & & & & & & & & & & & \\
\hline$s_{g}$ & -0.504 & 1.000 & & & & & & & & & & & & \\
\hline$x_{R}$ & $0.945^{\mathrm{a}}$ & $-0.613^{\mathrm{a}}$ & 1.000 & & & & & & & & & & & \\
\hline$n$ & 0.404 & $-0.977^{\mathrm{a}}$ & 0.508 & 1.000 & & & & & & & & & & \\
\hline$x_{10}$ & 0.491 & $-0.982^{\mathrm{a}}$ & $0.580^{\mathrm{a}}$ & $0.993^{\mathrm{a}}$ & 1.000 & & & & & & & & & \\
\hline$x_{50}$ & $0.788^{\mathrm{a}}$ & $-0.918^{\mathrm{a}}$ & $0.865^{\mathrm{a}}$ & $0.865^{\mathrm{a}}$ & $0.905^{\mathrm{a}}$ & 1.000 & & & & & & & & \\
\hline$I_{u}$ & 0.396 & $-0.965^{\mathrm{a}}$ & 0.503 & $0.997^{\mathrm{a}}$ & $0.988^{\mathrm{a}}$ & $0.860^{\mathrm{a}}$ & 1.000 & & & & & & & \\
\hline$N_{s g}$ & $0.788^{\mathrm{a}}$ & $-0.918^{\mathrm{a}}$ & $0.865^{\mathrm{a}}$ & $0.865^{\mathrm{a}}$ & $0.905^{\mathrm{a}}$ & $0.999^{\mathrm{a}}$ & $0.860^{\mathrm{a}}$ & 1.000 & & & & & & \\
\hline$R S_{m}$ & $-0.523^{\mathrm{a}}$ & $0.991^{\mathrm{a}}$ & $-0.604^{\mathrm{a}}$ & $-0.986^{\mathrm{a}}$ & $-0.995^{\mathrm{a}}$ & $-0.920^{\mathrm{a}}$ & $-0.978^{\mathrm{a}}$ & $-0.920^{\mathrm{a}}$ & 1.000 & & & & & \\
\hline$C_{u}$ & $-0.523^{\mathrm{a}}$ & $0.983^{\mathrm{a}}$ & $-0.586^{\mathrm{a}}$ & $-0.977^{\mathrm{a}}$ & $-0.990^{\mathrm{a}}$ & $-0.906^{\mathrm{a}}$ & $-0.965^{\mathrm{a}}$ & $-0.906^{\mathrm{a}}$ & $0.995^{\mathrm{a}}$ & 1.000 & & & & \\
\hline$C_{g}$ & -0.441 & $0.830^{\mathrm{a}}$ & -0.444 & $-0.829^{\mathrm{a}}$ & $-0.853^{\mathrm{a}}$ & $-0.733^{\mathrm{a}}$ & $-0.805^{\mathrm{a}}$ & $-0.733^{\mathrm{a}}$ & $0.845^{\mathrm{a}}$ & $0.879^{\mathrm{a}}$ & 1.000 & & & \\
\hline$S T D_{h}$ & $-0.547^{\mathrm{a}}$ & $0.991^{\mathrm{a}}$ & $-0.626^{\mathrm{a}}$ & $-0.982^{\mathrm{a}}$ & $-0.994^{\mathrm{a}}$ & $-0.931^{\mathrm{a}}$ & $-0.974^{\mathrm{a}}$ & $-0.931^{\mathrm{a}}$ & $0.999^{\mathrm{a}}$ & $0.994^{\mathrm{a}}$ & $0.846^{\mathrm{a}}$ & 1.000 & & \\
\hline$S T D_{l}$ & -0.473 & $0.987^{\mathrm{a}}$ & $-0.554^{\mathrm{a}}$ & $-0.991^{\mathrm{a}}$ & $-0.995^{\mathrm{a}}$ & $-0.892^{\mathrm{a}}$ & $-0.982^{\mathrm{a}}$ & $-0.892^{\mathrm{a}}$ & $0.996^{\mathrm{a}}$ & $0.995^{\mathrm{a}}$ & $0.874^{\mathrm{a}}$ & $0.994^{\mathrm{a}}$ & 1.000 & \\
\hline$S T D_{t}$ & -0.504 & $0.990^{\mathrm{a}}$ & $-0.585^{\mathrm{a}}$ & $-0.989^{\mathrm{a}}$ & $-0.996^{\mathrm{a}}$ & $-0.910^{\mathrm{a}}$ & $-0.980^{\mathrm{a}}$ & $-0.910^{\mathrm{a}}$ & $0.999^{\mathrm{a}}$ & $0.996^{\mathrm{a}}$ & $0.863^{\mathrm{a}}$ & $0.998^{\mathrm{a}}$ & $0.999^{\mathrm{a}}$ & 1.000 \\
\hline
\end{tabular}

Designations of variables are described in the footnote to Table 1

${ }^{\text {a }}$ Statistical significance at $\mathrm{p}$-value $=0.05$

clearance or speed and product classification screen opening dimensions [46].

\section{Physicochemical Properties of Pellets}

The milled biomass and pellet parameters were statistically significantly different (at $\mathrm{p} \leq 0.0001$ ). Based on the Duncan test, it was found that almost all values created a separate homogenous group (Table 3).

After pressure agglomeration of the biomass, the average moisture in the pellets material decreased by $0.50 \%$ w.b., and reached the absolute values for hay, straw, and their blend, equal to $5.56 \pm 0.15,5.56 \pm 0.20$, and $5.87 \pm 0.26 \%$ w.b., respectively. This may be the result of random sampling evidenced by the fact that the moisture of pellets made of hay and straw was higher than single biomass components. Minor moisture decreases were documented in pellet materials compared to shredded material could be due to the lower pressures of compaction, as evidenced by the low values of pellet durability coefficients (92.68-93.59\%) (Table 3). In other studies of the same type of biomass [16], the reduction of the moisture content in pellet materials was $2.57 \%$, while the addition of calcium carbonate led to a $6.44 \%$ reduction. Calcium carbonate significantly decreased the moisture of the material in produced pellets. Differences in the material's moisture content, and its susceptibility to changes under the influence of calcium carbonate, can affect the biomass agglomeration and consequently, the mechanical durability and pellet strength. Comparison of the obtained results with previously published data showed that yielded milled biomass and pellets moisture values were approximately two times lower than values obtained in other laboratory tests
[46]. Mani et al. [1] observed that moisture in the material during the compaction increases the bonding via van der Wall's forces, thereby increasing the contact area of particles. Compressive force, particle size and moisture content of $12-15 \%$ w.b. significantly affected the pellet density of barley straw, corn stover and switchgrass. However, different particle sizes of wheat straw did not have any significant difference on pellets density [54]. The low material moisture content $(5-10 \%)$ resulted in denser, more stable and durable products compared to those produced from biomass of higher moisture content (15\%). In the laboratory single pellet press [55] the raw material moisture content was the dominant factor for pellet density and compression strength. For reed canary grass, optimal pellet density occurred at $5.2 \%$ and $8.5 \%$ moisture content for compression pressure of $300 \mathrm{MPa}$ and $400 \mathrm{MPa}$. For rice straw, the optimal moisture content range was between $13 \%$ and $20 \%$ under a forming temperature of 60 or $80{ }^{\circ} \mathrm{C}$. The optimal particle size was between 10 and $20 \mathrm{~mm}$, considering the time and energy required for shredding, although the particle size did not significantly affect the yield ratio and durability of the rice straw pellets [30]. Optimum moisture contents for dense barley straw pellets production were higher and proved to be in the range of 19-23\% [56].

Although the values of the durability coefficients of the pellets were within a narrow range, they were statistically significantly different for all biomass types, thereby yielding the highest average value of $93.59 \%$ for straw materials, and the lowest value of $92.68 \%$ for blended materials. Taking into account the standard deviation values for hay and straw, it can be stated that the statistical significance of the differences is marginal. Considering the minor difference 
in moisture content for milled biomass, it can be stated that pellets durability has been logically changed. It can be assumed that the pellets durability is similar, when the changes are small. Blending hay and straw has not resulted in the expected synergy that would lead to the strengthening of the bonds between the particles of different types of biomasses. Particle sizes for biomass blends were the largest $(0.69 \mathrm{~mm})$, while the corresponding sizes for hay and straw were somewhat smaller, $0.65 \mathrm{~mm}$ and $0.63 \mathrm{~mm}$, respectively. Thus, it is confirmed that the proportion of finer particles in the straw, but with interlaced longer particles (Fig. 1), i.e. the most diverse distribution of particle dimensions relative to hay and blend, characterized by a dimensionless standard deviation ( 2.95 vs. 2.10 and 2.37, respectively), allowed for slightly better bonds between particles and production of pellets with a slightly higher durability $(93.59 \%)$. According to Kraszkiewicz et al. [57], the durability of pellets made of triticale straw, hay, and cereal blends with a moisture content of $11.5-14.8 \%$ w.b., were $96.00 \%, 97.67 \%$, and $98.33 \%$, respectively. The durability coefficient of plant biomass pellets was within the range of $86.60-98.50 \%$ [60].

The specific and bulk densities of pellets were the highest for products manufactured from biomass blends and attained values of $1102 \mathrm{~kg} \mathrm{DM} \mathrm{m}^{-3}$ and $514 \mathrm{~kg} \mathrm{DM} \mathrm{m}^{-3}$, respectively. The specific density of pellets made of hay and straw were $1034 \mathrm{~kg} \mathrm{DM} \mathrm{m}^{-3}$ and $974 \mathrm{~kg} \mathrm{DM} \mathrm{m}^{-3}$, respectively, while the bulk density values were $478 \mathrm{~kg} \mathrm{DM} \mathrm{m}^{-3}$ and $498 \mathrm{~kg} \mathrm{DM} \mathrm{m}^{-3}$, respectively. According to the PN-EN ISO 17225-6:2014-08 standard [58], the bulk density of non-wooden pellets is required $\geq 600 \mathrm{~kg} \mathrm{~m}^{-3}$. The Swedish SS 187120 standard [59] requires the bulk density to be higher than $500 \mathrm{~kg} \mathrm{~m}^{-3}$ (for the "industrial" quality; 3rd class of pellets). Thus, the bulk density of pellets made of hay and straw were even lower than those required by the Swedish standard. Similar pellet bulk density results within the range of $323-567 \mathrm{~kg} \mathrm{~m}^{-3}$ produced from plant biomass (wheat straw, rape straw, corn straw, meadow hay, wheat bran, cereal, and rape waste) were obtained by Niedziółka and Szpryngiel [60].

Based on the durability and density of pellets, the quality of the products can be assessed reliably. The properties and parameters of the pelletiser, such as the mechanics of compacting roll pressure, dimensions of the die, channel geometry in the die, method of feeding and moisturising the raw material, before compaction and dosage of the raw material to the die were comparable. Additionally, the durability and density of the pellets depended mainly on the properties of the processed biomass. The significantly higher particle sizes of the blend pellets $(0.69 \mathrm{~mm})$ compared to those of hay and straw $(0.65 \mathrm{~mm}$ and $0.63 \mathrm{~mm}$, respectively), likely led to the lower durability of the pellets from blend than from single biomass types. However, it should be emphasised that biomass particle sizes were much smaller than the required size of $3.2 \mathrm{~mm}$ [1]. It is generally suggested that fine particles should not comprise more than $10-20 \%$ of feed as they reduce the quality of pellet and causes friction on the pellet die [9]. Pellets produced from fine particles show greater compression and abrasive strength and durability [14, 19, 27, 51, 57]. Mani et al. [54] found that particle size significantly affects the density of pellets made from barley straw, corn stover, and switchgrass, but not in the case of wheat straw. Jannasch et al. [34] found that switchgrass pellet hardness moderately increased with a decrease in particle screen size from 3.2 to $2.8 \mathrm{~mm}$. Based on the current research results, it could be stated that increased milling improves the susceptibility of biomass to the pressure agglomeration process [12], but an increased fine fraction of small particles and dust is an undesirable property [16]. A combination of fine and medium grind has been reported to be necessary to pellet qualities as the mixture will make inter-particle bonding with nearly no inter-particle spaces. Particles having a long shape were reported to have advantages as they may stick together strongly through in interlocking mechanism $[1,13,17]$. The results presented by Lisowski and Świętochowski [61] on the durability coefficient values have led to the inference that the separation of large particles from the Miscanthus mixture intended for pellet production did not cause a statistically significant difference in the durability of the products.

In conclusion, the quality of the pelletized fuels is confirmed by two main factors; density and durability [62]. As mentioned, high bulk density of a pellet implies higher energy density of the fuels, while mechanical durability represents the higher resistance of the pellets against a variety of external loads such as abrasion, shear, bending and impact forces applied during handling and transportation. Variations in specific pellet density and bulk density significantly affect the fuel or feeding quantity and quality during transport and storage or when it is placed on the belt conveyer of power plants and in the bioreactors for biofuel and bioenergy production. Therefore, the production of pellets should be carried out in such conditions to reduce pellet density variations [5].

Calorific values of pellets made of hay and straw blend were close to the arithmetic averages of the calorific values of pellets made of hay or straw alone. The corresponding calorific values were $16.64 \mathrm{MJ} \mathrm{kg}^{-1}, 16.07 \mathrm{MJ} \mathrm{kg}^{-1}$, and $17.00 \mathrm{MJ} \mathrm{kg}^{-1}$, respectively. Moreover, Niedziółka and Szpryngiel [63] reported average calorific values for wheat and rye straw of $17.05 \mathrm{MJ} \mathrm{kg}^{-1}$ and $16.35 \mathrm{MJ} \mathrm{kg}^{-1}$, respectively, and values of $16.1-17.5 \mathrm{MJ} \mathrm{kg}^{-1}$ for plant biomass.

On the basis of the Pearson correlation coefficient values (Table 6), it can be concluded that the calorific value correlates with the pellet bulk density (0.637) but did not achieve cohesion with the pellet specific density $(-0.281)$, despite the stated correlation between these densities (0.392). 
Table 6 Correlation matrix for geometric mean of particle length $x_{g}$, dimensionless standard deviation $s_{g}$, biomass moisture content $M C_{b}$, pellet moisture content $M C_{p}$, durability coefficient $D U$, pellet specific density $\rho_{j p}$, pellet bulk density $\rho_{b p}$, and caloric value $Q_{p}$

\begin{tabular}{lrrrrrrrrr}
\hline Parameter & Biomass & \multicolumn{1}{c}{$x_{g}$} & \multicolumn{1}{c}{$s_{g}$} & $M C_{b}$ & $M C_{p}$ & $D U$ & $\rho_{j p}$ & $\rho_{b p}$ & $Q_{p}$ \\
\hline Biomass & 1.000 & & & & & & & & \\
$x_{g}{ }^{*}$ & 0.776 & 1.000 & & & & & & & \\
$s_{g}$ & 0.564 & $-0.475^{\mathrm{a}}$ & 1.000 & & & & & & \\
$M C_{b}$ & 0.274 & $0.681^{\mathrm{a}}$ & $-0.611^{\mathrm{a}}$ & 1.000 & & & & & \\
$M C_{p}$ & 0.503 & $0.438^{\mathrm{a}}$ & 0.090 & $0.542^{\mathrm{a}}$ & 1.000 & & & & \\
$D U$ & -0.386 & $-0.450^{\mathrm{a}}$ & $0.506^{\mathrm{a}}$ & $-0.412^{\mathrm{a}}$ & -0.138 & 1.000 & & & \\
$\rho_{j p}$ & 0.461 & $0.705^{\mathrm{a}}$ & $-0.540^{\mathrm{a}}$ & $0.655^{\mathrm{a}}$ & $0.368^{\mathrm{a}}$ & $-0.674^{\mathrm{a}}$ & 1.000 & & \\
$\rho_{b p}$ & 0.972 & $0.483^{\mathrm{a}}$ & $0.350^{\mathrm{a}}$ & 0.248 & $0.516^{\mathrm{a}}$ & -0.295 & $0.392^{\mathrm{a}}$ & 1.000 & \\
$Q_{p}$ & 0.594 & -0.169 & $0.918^{\mathrm{a}}$ & $-0.423^{\mathrm{a}}$ & 0.090 & $0.343^{\mathrm{a}}$ & -0.281 & $0.637^{\mathrm{a}}$ & 1.000 \\
\hline
\end{tabular}

* $x_{g}$ geometric mean of biomass particle size, $s_{g}$ dimensionless standard deviation, $M C_{b}$ biomass moisture content, $M C_{p}$ pellet moisture content, $D U$ durability coefficient, $\rho_{j p}$ specific pellet density, $\rho_{b p}$ bulk density, $Q_{p}$ calorific value;

${ }^{\text {a }}$ Statistical significance at $\mathrm{P}$-value $=0.05$

Table 7 The values of regression coefficients and their statistical assessments for the non-linear function $D U=b_{0}+b_{1} M C_{p}^{2}+b_{2} x_{g} \rho_{j p} / \rho_{b p}+b_{3} M C_{p} x_{g} \rho_{j p} / \rho_{b p}$ of the durability coefficient versus the pellet moisture content $M C_{p}$, and the ratio of $x_{g} \rho_{j p} /$ $\rho_{b p}$

\begin{tabular}{|c|c|c|c|c|c|c|}
\hline $\begin{array}{l}\text { Regression coef- } \\
\text { ficient }\end{array}$ & Evaluation & Error & $\begin{array}{l}\text { Student's } t \text { test } \\
\text { value }\end{array}$ & $\mathrm{P}$ value & $\begin{array}{l}\text { Lower confidence inter- } \\
\text { val value }\end{array}$ & $\begin{array}{l}\text { Upper confi- } \\
\text { dence interval } \\
\text { value }\end{array}$ \\
\hline$b_{0}$ & 70.32 & 8.08 & 8.70 & $<0.0001$ & 54.00 & 86.64 \\
\hline$b_{1}$ & 0.82 & 0.25 & 3.23 & 0.0024 & 0.31 & 1.34 \\
\hline$b_{2}$ & 36.37 & 12.07 & 3.01 & 0.0044 & 12.00 & 60.73 \\
\hline$b_{3}$ & -6.89 & 2.14 & -3.21 & 0.0025 & -11.21 & -2.56 \\
\hline
\end{tabular}

Specific and bulk densities of pellets were correlated with the geometric means of the particle lengths $(0.705$ and 0.483 , respectively).

The durability coefficient was negatively correlated with the geometric means of the particle length $(-0.450)$, and the milled biomass moisture content $(-0.412)$. The smaller of the geometric particles size and the lower material moisture were, the higher the durability of the pellets was, but it should be emphasized that the variation of these parameters, especially the moisture, was insignificant. This inference confirms the previous considerations and literature data $[14,19,27,51,57]$, but it should be added that the stability of pellets has a positive effect on the particle size diversity characterized by dimensionless standard deviations $\left(s_{g}\right)$ for which the correlation coefficient is 0.506 .

The results of the statistical analysis and correlation matrix will determine the approach used for the modelling of the durability of pellets, $D U$, versus the pellet moisture content, $M C_{p}$, and the relations of $x_{g} \rho_{j p} / \rho_{b p}$ (Table 7; Fig. 2). All regression coefficients were statistically significant.

From the surface plotted in Fig. 2, it can be observed that pellet durability increases with pellet moisture content $M C_{p}$, especially for small values of $x_{g} \rho_{j p} / \rho_{b p}$. These relations are the outcomes of small differences in moisture content since the moisture of milled biomass was too small to achieve good particle plasticity under thermal, biomass de-crystallisation. This was a consequence of friction between particles

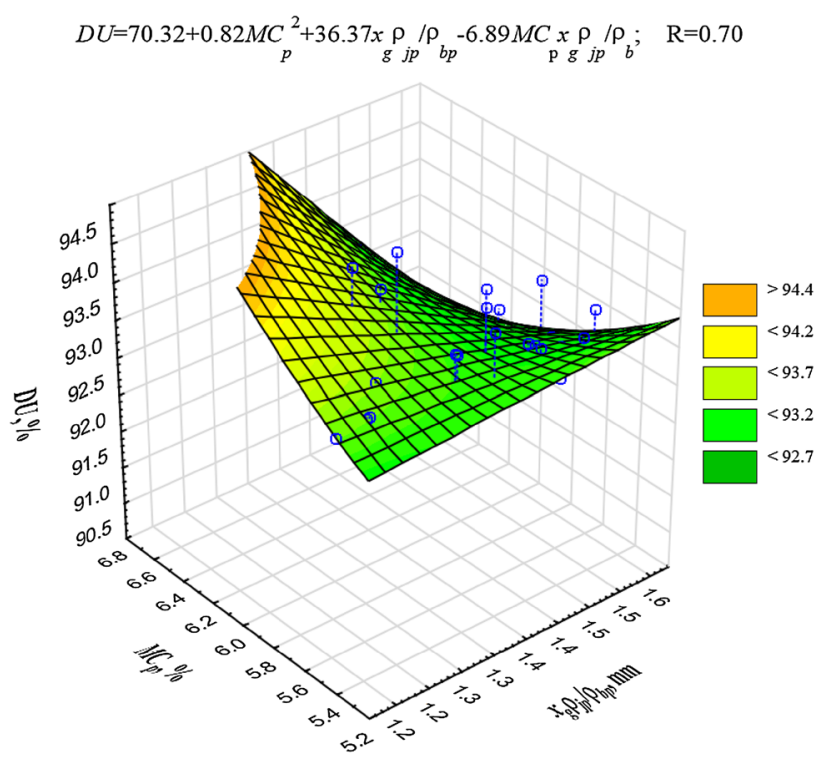

Fig. 2 Characteristic of durability coefficient versus pellet moisture content $M C_{p}$ and the relations of $x_{g} \rho_{j p} / \rho_{b p}$ 
and the walls of the die chamber, and friction between adjacent particles moving under the pressure of the roller on the material. On the basis of literature it can be stated that pellet durability can be affected by the feedstock characteristics, the moisture content, shape and particle size distribution, biomass true density, pre-processing treatment, and by pelleting conditions, including the use of binders, feedstock mixes, temperatures or compaction pressures $[6,12,14]$. Correspondingly, there is a need for further research to develop mathematical models based on the physical properties of the milled plant material, and the working parameters of the pelletiser.

In the summary of the analysis of research results and their discussions, it can be concluded that the mechanical durability of pellets was greater for smaller particle sizes and lower moisture contents. Under these conditions the specific pellet density and bulk density were higher, and the calorific value of the pellet material was greater. The durability of straw pellets was the largest, which was probably related to the large variation in particles size. With a significant proportion of fine particles in the straw, there were quite a lot of longer particles that favoured longer-lasting inter-particle combinations. In the durability test, pellets are rubbed against the inside surfaces of the apparatus and between pellets, but the pellets are also subjected to falls from the inner diagonal barrier under the influence of gravity. In particular, the impact of pellets on the steel surface of apparatus may cause the fracture of pellets. Logical analysis allows to suppose that pellets made of material of smaller particle sizes can divide on the border between particles, and with larger particle sizes, the split of pellets can also occur over the length of particles which strength is most often greater than the strength of bonds between particles. This assumption requires to conduct targeted research.

\section{Conclusions}

The moisture content of pellets (5.56-5.87\% w.b.) was found to be lower than that of milled biomass (5.68-6.56\% w.b.), which indicates that the thermal process, resulting from friction, occurred during the pressure agglomeration process. Pellet properties of the blend were not adequately represented by the arithmetic means of their constituent components. The durability of the pellets made of straw was the highest at $93.59 \%$, and pellets made from the blend of straw and hay had the lowest durability value at $92.68 \%$. The differences were minor.

The specific and bulk densities of pellets produced from the blend of hay and straw were the highest, with values of $1102 \mathrm{~kg} \mathrm{~m}^{-3}$ and $514 \mathrm{~kg} \mathrm{~m}^{-3}$, respectively. The highest net calorific value of $17.00 \mathrm{MJ} \mathrm{kg}^{-1}$ that was analogous to gross calorific value, was associated with pellets made from straw. The calorific value of pellets made from hay was $16.07 \mathrm{MJ} \mathrm{kg}^{-1}$. This value was close to the value for pellets that were made from the blend of hay and straw (16.64 $\mathrm{MJ} \mathrm{kg}^{-1}$ ), and close to the average calorific values of the two constituent components of straw and hay.

On the basis of the correlation results, the non-linear mathematical model developed for the durability coefficient for pellets $D U$ versus the pellet moisture content $M C_{p}$, and the ratio $x_{g} \rho_{j p} / \rho_{b p}$, indicated the presence of moisture effects, especially at small values of the ratio $x_{g} \rho_{j p} / \rho_{b p}$.

Acknowledgements This research was partially supported by the Ministry of Science and Higher Education in Poland.

\section{Compliance with Ethical Standards}

Conflict of interest The authors declare that there is no financial or commercial conflict of interest.

Open Access This article is distributed under the terms of the Creative Commons Attribution 4.0 International License (http://creativeco mmons.org/licenses/by/4.0/), which permits unrestricted use, distribution, and reproduction in any medium, provided you give appropriate credit to the original author(s) and the source, provide a link to the Creative Commons license, and indicate if changes were made.

\section{References}

1. Mani, S., Tabil, L.G., Sokhansanj, S.: An overview of compaction of biomass grinds. Powder Hand. Process. 15(3), 160-168 (2003)

2. Mani, S., Tabil, L.G., Sokhansanj, S.: Specific energy requirement for compacting corn stover. Bioresour. Technol. 97, 1420-1426 (2006)

3. Miao, Z., Phillips, J.W., Grift, T.E.: Measurement of mechanical compressive properties and densification energy requirement of Miscanthus $\times$ giganteus and switchgrass. Bioenergy Res. 8, 152-164 (2015)

4. Niedziółka, I., Zaklika, B., Kachel-Jakubowska, M., Kraszkiewicz, A.: Impact of physical properties of selected plant raw materials on the quality and energy intensity of briquettes produced. Ann. WULS - SGGW, Agric. (Agric. Forest. Eng.) 68, 51-59 (2016)

5. Larsson, S.H., Thyrel, M., Geladi, P., Lestander, T.A.: High quality biofuel pellet production from pre-compacted low density raw materials. Bioresour. Technol. 99, 7176-7182 (2008)

6. Miranda, T., Montero, I., Sepúlveda, F.J., José Ignacio Arranz, J.I., Rojas, C.V., Nogales, S.: A review of pellets from different sources. Materials 8, 1413-1427 (2015)

7. Ciolkosz, D., Hilton, R., Swackhamer, C., Yi, H.-J., Puri, V.M., Swomley, D., Roth, G.: Farm-scale biomass pelletizer performance for switchgrass pellet production. Appl. Eng. Agr. 31(4), 559-567 (2015)

8. Lisowski, A., Grela, M., Sypuła, M., Świętochowski, A., Dąbrowska-Salwin, M., Stępień, W., Korupczyński, R.: Pellets and briquettes from fruit trees wood. Ann. WULS - SGGW, Agric. (Agric. Forest Eng.) 66, 127-136 (2015) 
9. Kaliyan, N., Morey, R.V.: Factors affecting strength and durability of densified biomass products. Biomass Bioenergy 33, 337-359 (2009)

10. Kulig, R., Skonecki, S., Łysiak, G.: The effect of binder addition on the parameters of compacted poplar wood sawdust. Teka Commission Motor Agric 12, 303-309 (2012)

11. Peleg, M., Mannheim, C.H.: Effect of conditioners on the flow properties of powdered sucrose. Powder Technol. 7(1), 45-50 (1973)

12. Tumuluru, J.S., Wright, C.T., Hess, J.R., Kenney, K.L.: A review of biomass densification systems to develop uniform feedstock commodities for bioenergy application. Biofuel Bioprod. Biorefining 5(6), 683-707 (2011)

13. Stelte, W., Sanadi, A.R., Shang, L., Holm, J.K., Ahrenfeldt, J., Henriksen, U.B.: Recent developments in biomass pelletisation-a review. Bioresources 7(3), 4451-4490 (2012)

14. Whittaker, C., Shield, I.: Factors affecting wood, energy grass and straw pellet durability - a review. Renew. Sustain. Energy Rev. 71, 1-11 (2017)

15. Lisowski, A., Figurski, R., Kostyra, K., Sypuła, M., Klonowski, J., Świętochowski, A., Sobotka, T.: Effect of maize variety and harvesting conditions on the maize chopping process, compacting susceptibility and quality of silage designed for biogas production. Ann. WULS - SGGW, Agric. (Agric. Forest Eng.) 64, 25-38 (2014)

16. Lisowski, A., Matkowski, P., Świętochowski, A., DąbrowskaSalwin, M.: The characteristics of shredded straw and hay and their mix. Ann. WULS - SGGW, Agric. (Agric. Forest Eng.) 68, 41-49 (2016)

17. Stelte, W., Holm, J.K., Sanadi, A.R., Barsberg, S., Ahrenfeldt, J., Henriksen, U.B.: A study of bonding and failure mechanisms in fuel pellets from different biomass resources. Biomass Bioenergy 35(2), 910-918 (2011)

18. Scatolino, M.V., Neto, C., Protásio, L.F., Carneiro, T.P., Andrade, A.C.O., Guimarães, C.R., Júnior, J.B., Mendes, L.M.: Options for generation of sustainable energy: production of pellets based on combinations between Lignocellulosic biomasses. Waste Biomass Valoriz. 9, 479-489 (2018)

19. Kaliyan, N., Morey, R.V.: Natural binders and solid bridge type binding mechanisms in briquettes and pellets made from corn stover and switchgrass. Bioresour. Technol. 101, 1082-1090 (2010)

20. Aniszewska, M., Gendek, A.: Logistics of delivery of cones of selected species of forest trees. Part 2: cone transport. Ann. WULS - SGGW, Agric. (Agric. Forest Eng.) 68, 113-121 (2016)

21. Aniszewska, M., Gendek, A.: Logistics of the supplies of selected forest tree species' cones. Part 1. Cone density and substitution coefficient. Ann. WULS - SGGW, Agric. (Agric. Forest Eng.) 67, 121-130 (2016)

22. Dufaud, O., Bideau, D., Le Guyadec, F., Corriou, J.P., Perrin, L., Caleyron, A.: Self ignition of layers of powder mixtures. Powder Technol. 254, 160-169 (2014)

23. Lisowski, A., Dąbrowska-Salwin, M., Ostrowska-Ligęza, E., Nawrocka, A., Stasiak, M., Świętochowski, A., Klonowski, J., Sypuła, M., Lisowska, B.: Effects of the biomass moisture content and pelleting temperature on the pressure-induced agglomeration process. Biomass Bioenergy 107, 376-383 (2017)

24. D'Amours, L.D., Savoie, P.: Density profile of corn silage in bunker silos. Can Biosyst Eng. 47, 221-228 (2005)

25. Holmes, B.J., Muck, R.E.: Factors affecting bunker silo densities. Appl. Eng. Agric. 16(6), 613-619 (2000)

26. Savoie, P., Muck, R.E., Holmes, B.J.: Laboratory assessment of bunker silo density, part II: whole-plant corn. Appl. Eng. Agric. 20(2), 165-171 (2004)
27. Kong, L., Xiong, Y., Liu, T., Tu, Y., Tian, S., Sun, L., Chen, T.: Effect of fiber natures on the formation of "solid bridge" for preparing wood sawdust derived biomass pellet fuel. Fuel Process. Technol. 144, 79-84 (2016)

28. Arshadi, M., Gref, R., Geladi, P., Dahlqvist, S.-A., Lestander, T.: The influence of raw material characteristics on the industrial pelletizing process and pellet quality. Fuel Process. Technol. 89, 1442-1447 (2008)

29. Bitra, V.S.P., Womac, A.R., Chevanan, N., Miu, P.I., Igathinathane, C., Sokhansanj, S., Smith, D.R.: Direct mechanical energy measures of hammer mill comminution of switchgrass, wheat straw, and corn stover and analysis of their particle size distributions. Powder Technol. 193, 32-45 (2009)

30. Ishii, K., Furuichi, T.: Influence of moisture content, particle size and forming temperature on productivity and quality of rice straw pellets. Waste Manag. 34, 2621-2626 (2014)

31. Theerarattananoon, K., Xu, F., Wilson, J., Ballard, R., Mckinney, L., Staggenborg, S., Vadlani, P., Pei, Z.J., Wang, D.: Physical properties of pellets made from sorghum stalk, corn stover, wheat straw, and big bluestem. Ind. Crop. Prod. 33, 325-332 (2011)

32. Adapa, P., Tabil, L., Schoenau, G.: Compaction characteristics of barley, canola, oat and wheat straw. Biosyst. Eng. 104, 335-344 (2009)

33. Kaliyan, N., Morey, R.V.: Constitutive model for densification of corn stover and switchgrass. Biosyst. Eng. 104, 47-63 (2009)

34. Jannasch, R., Quan, Y., Samson, R.: A process and energy analysis of pelletizing switchgrass. Final report. http://www.reapcanada .com/online_library/Reports\%20and $\% 20$ Newsletters/Bioen ergy/11\%20A\%20Process.pdf (2001). Accessed June 2018

35. Karamchandani, A., Yi, H., Puri, V.M.: Comparison and explanation of predictive capability of pellet quality metrics based on fundamental mechanical properties of ground willow and switchgrass. Adv. Powder Technol. 27(4), 1411-1417 (2016)

36. Moya, R., Rodríguez-Zúńiga, A., Tenorio, C., Valdez, J., Valaert, J.: Pellets evaluation made from tropical-climate agricultural and forestry crops of Costa Rica with a domestic stove. Waste Biomass. Valoriz. 6, 1037-1046 (2015)

37. Gil, M.V., Oulego, P., Casal, M.D., Pevida, C., Pis, J.J., Rubiera, F.: Mechanical durability and combustion characteristics of pellets from biomass blends. Bioresour. Technol. 101, 8859-8867 (2010)

38. Monedero, E., Portero, H., Lapuerta, M.: Pellet blends of poplar and pine sawdust: effects of material composition, additive, moisture content and compression die on pellet quality. Fuel Process. Technol. 132, 15-23 (2015)

39. Harun, N.Y., Afzal, M.T.: Effect of particle size on mechanical properties of pellets made from biomass blends. Procedia Eng. 148, 93-99 (2016)

40. Stasiak, M., Molenda, M., Bańda, M., Wiącek, J., Parafiniuk, P., Gondek, E.: Mechanical and combustion properties of sawduststraw pellets blended in different proportions. Fuel Process. Technol. 156, 366-375 (2017)

41. Wang, Y., Wu, K., Sun, Y.: Pelletizing properties of wheat straw blending with rice straw. Energy Fuels 31(5), 5126-5134 (2017)

42. http://polskaradapelletu.org/en/czlonkowie/. Accessed June 2018

43. Igliński, B., Iglińska, A., Kujawski, W., Buczkowski, R., Cichosz, M.: Bioenergy in Poland. Renew. Sustain. Energy Rev. 15(6), 2999-3007 (2011)

44. ASABE Standards: ASAE S358.2: Moisture Measurement-Forages, pp. 780-78. ASABE, St. Joseph (2011)

45. ASABE Standards: ANSI/ASAE S319.4: Method of Determining and Expressing Fineness of Feed Materials by Sieving, p. 776. ASABE, St. Joseph (2011)

46. Lisowski, A., Kostrubiec, M., Dąbrowska-Salwin, M., Świętochowski, A.: The characteristics of shredded straw and hay 
biomass. Part 2-the finest particles. Waste Biomass Valoriz. 9, 115-121 (2018)

47. Rosin, P., Rammler, E.: The laws governing the fineness of powdered coal. J. Instrum. Fuel 7, 29-36 (1933)

48. PN-EN 15407:2011: Solid Recovered Fuels. Methods for the Determination of Carbon $(\mathrm{C})$, Hydrogen $(\mathrm{H})$ and Nitrogen $(\mathrm{N})$ Content. CEN European CS, Brussels (2011)

49. PN-EN: ISO 17831-1:2016-01: Solid Biofuels-Determination of Mechanical Durability of Pellets and Briquettes-Part 1: Pellets. CEN European CS, Brussels (2016)

50. Chaloupková, V., Ivanova, T., Ekrt, O., Kabutey, A., Herák, D.: Determination of particle size and distribution through imagebased macroscopic analysis of the structure of biomass briquettes. Energies 11(2), 331 (2018)

51. Wiacek, J., Stasiak, M.: Effect of the particle size ratio on the structural properties of granular mixtures with discrete particle size distribution. Granular Matter (2018). https://doi.org/10.1007/ s10035-018-0800-7

52. Blott, S.J., Pye, K.: Gradistat: a grain size distribution and statistics package for the analysis of unconsolidated sediments. Earth Surf. Process. Landforms 26, 1237-1248 (2001)

53. Folk, R.L., Ward, W.C.: Brazos river bar: a study in the significance of grain size parameters. J. Sediment. Petrol. 27, 3-26 (1957)

54. Mani, S., Tabil, L.G., Sokhansanj, S.: Effects of compressive force, particle size and moisture content on mechanical properties of biomass pellets from grasses. Biomass Bioenergy 30, 648-654 (2006)

55. Huang, Y., Finell, M., Larsson, S., Wang, X., Zhang, J., Wei, R., Liu, L.: Biofuel pellets made at low moisture content-influence of water in the binding mechanism of densified biomass. Biomass Bioenergy 98, 8-14 (2017)

56. Serrano, C., Monedero, E., Lapuerta, M., Portero, H.: Effect of moisture content, particle size and pine addition on quality parameters of barley straw pellets. Fuel Process. Technol. 92, 699-706 (2011)

57. Karszkiewicz, A., Kachel-Jakubowska, M., Szpryngiel, M., Niedziółka, I.: The analysis of the selected quality properties of pellets made of plant raw materials. Agric. Eng. 2(143), 167-173 (2013)

58. PN-EN ISO 17225-6:2014-08: Solid Biofuels-Fuel Specifications and Classes-Part 6: Graded Non-woody Pellets. ISO, Geneva (2014)

59. SS 1871 20: Swedish Standard, Biofuels and Peat-Fuel Pellets-Classification (2008)

60. Niedziółka, I., Szpryngiel, M.: Assessment of quality properties of plant biomass pellets. Agric. Eng. 2(136), 267-276 (2012)

61. Lisowski, A., Świętochowski, A.: Mechanical durability of pellets and briquettes made from a miscanthus mixture without and with the separation of long particles. Polish Soc. Agric. Eng. 1, 93-100 (2014)

62. Madadian, E., Akbarzadeh, A.H., Orsat, V., Lefsrud, M.: Pelletized composite wood fiber mixed with plastic as advanced solid biofuels: Physico-chemo-mechanical analysis. Waste biomass Valoriz. (2017). https://doi.org/10.1007/s12649-017-0080-1

63. Niedziółka, I., Szpryngiel, M.: Assessment of energy consumption of pellets and briquettes production in compressing devices. Agric. Eng. 2(150), 145-154 (2014) 